Check for updates

Cite this: RSC Adv., 2019, 9, 185

Received 16th November 2018 Accepted 14th December 2018

DOI: $10.1039 / \mathrm{c} 8 \mathrm{ra09457h}$

rsc.li/rsc-advances

\section{Imidazolyl activated carbon refluxed with ethanediamine as reusable heterogeneous catalysts for Michael addition}

\author{
Wenzhu Liu, (D) a Jiafu Xiao, (D) a Qiong Xu, ${ }^{\text {*a }}$ Xianxiang Liu, (D) a Sheng Zhong, ${ }^{\text {b }}$ \\ Hua Huang, ${ }^{b}$ Min Zheng, ${ }^{c}$ Steven Robert Kirk (D) ${ }^{a}$ and Dulin Yin ${ }^{\star a}$
}

\begin{abstract}
Imidazolyl activated carbon, denoted as $\mathrm{AC}-\mathrm{N}$, was prepared via oxidation of $\mathrm{AC}$ with $\mathrm{HNO}_{3}(\mathrm{AC}-\mathrm{O})$ and then refluxed with ethanediamine under mild conditions. The results showed that the $\mathrm{N}$ content of $\mathrm{AC}-\mathrm{N}$ was $10.3 \%$, and the surface alkali group density of $A C-\mathrm{N}$ was $0.96 \mathrm{mmol} \mathrm{g}^{-1}$ from $0.78 \mathrm{mmol} \mathrm{g}^{-1}$ carboxy group of $\mathrm{AC}-\mathrm{O}$ by Boehm titration. It was revealed that the basic functional groups on the $\mathrm{AC}-\mathrm{N}$ surface included imidazole and amine groups, from XPS and FT-IR. Evaluated with Michael addition of furfural, the catalytic performance of AC-N showed higher conversion and selectivity than that of commonly used base catalyst such as 2-methylimidazole and $\mathrm{KOH}$. Very remarkably, AC-N showed extraordinary recyclability, in that there was no decline of conversion and selectivity after being recycled 5 times.
\end{abstract}

\section{Introduction}

Activated carbon (AC) materials are known to have a highly developed pore structure, large specific surface area, changeable surface chemical characteristics and high surface activity, ${ }^{\mathbf{1 , 2}}$ and have been widely used in adsorption, ${ }^{3-7}$ catalysis $^{\mathbf{8 , 9}}$, electrode materials ${ }^{\mathbf{1 0}}$, and decoloration, ${ }^{\mathbf{1 1}}$ etc. It's been believed that the most attractive property of activated carbon materials is their controllable surface properties, with controlled amounts of aromatic rings and oxygen-containing functional groups. Acidic surface sites on AC have usually been generated by treatments in liquid media with oxidative agents such as $\mathrm{HNO}_{3},{ }^{12-14} \mathrm{H}_{2} \mathrm{SO}_{4}{ }^{15}\left(\mathrm{NH}_{4}\right)_{2} \mathrm{~S}_{2} \mathrm{O}_{8}{ }^{16}$ and $\mathrm{KMnO}_{4} \cdot{ }^{17}$ An alkali surface of activated carbon is enormously in demand in extensive specific areas and has attracted many researchers' interest. There were a number of studies related to the preparation of activated carbons by steeping or reaction with $\mathrm{KOH}$ and $\mathrm{NaOH} .{ }^{18-20}$ Park $^{21}$ prepared basic activated carbons with coconut shell AC in $\mathrm{NaOH}$ solution, and the surface $\mathrm{pH}$ was 10.2. Cazetta $^{22}$ prepared alkaline surface activated carbon by mixing coconut shell char with $\mathrm{NaOH}$ and the basic density was 0.73-0.75 $\mathrm{mmol} \mathrm{g}^{-1}$.

In recent years, some meaningful explorations found that an alkaline surface could be constructed by treating activated carbons with ammonia or amines, while the procedures known

${ }^{a}$ National and Local Joint Engineering Laboratory for New Petro-Chemical Materials and Fine Utilization of Resources, College of Chemistry and Chemical Engineering, Hunan Normal University, 410081, Changsha, China. E-mail: xuqiong@hunnu.edu. cn; dulinyin@126.com; Tel: +86 18942513809; +86 13808496387

${ }^{b}$ Hunan Changling Petrochemical S \& T Developing Co. Ltd, 414012, Yueyang, China ${ }^{c}$ Hunan First Normal University, 410205, Changsha, China to make active carbon surfaces basic usually involved treatment under high temperatures. Barbosa ${ }^{23}$ prepared carbon dots from cow manure and functionalized them with ethylenediamine, affording amide bonds that resulted in bright green fluorescence, which improved cellular selectivity for nucleoli staining. $\mathrm{GaO}^{24}$ prepared a series of mesoporous, N-containing carbon materials directly from pure chitin by means of carbonization at 400-1000 ${ }^{\circ} \mathrm{C}$ enriched with amine, amide, and pyrrolic functionalities. $\mathrm{Li}^{25}$ prepared nitrogen-doped activated carbons utilizing agricultural waste (corncob) as precursor under $\mathrm{N}_{2}$ flow with $\mathrm{NH}_{3}$ as a nitrogen source under $400-600{ }^{\circ} \mathrm{C}$, the $\mathrm{N}$ content was $2.97 \mathrm{wt} \%$ to $3.98 \mathrm{wt} \%$. Wang ${ }^{26}$ prepared $\mathrm{N}$-doped hierarchical porous carbon with urea at $180{ }^{\circ} \mathrm{C}$ in an autoclave and then immersed in potassium hydroxide solution: in this case, the $\mathrm{N}$ content was around $2.5 \%$. Lahaye ${ }^{27}$ provided activated carbon fibers with a basic surface by treatment with ammonia at $500-800{ }^{\circ} \mathrm{C}$ and the $\mathrm{N}$ content of the products was $0.94-4.06 \%$. Stöhr ${ }^{28}$ proposed that amination of activated carbons lead to the formation of $\mathrm{NH}_{2}$ or $\mathrm{NH}$ functional groups attached to the carbon rings at $600-900{ }^{\circ} \mathrm{C}$. Park ${ }^{29}$ prepared mesoporous nitrogen-doped activated carbon with (1-methyl-1 $H$-pyrrole-2-yl) methanol and $\mathrm{KOH}$ at $100-850{ }^{\circ} \mathrm{C}$, where the majority of the $\mathrm{N}$ was assigned to pyridinic and graphitic nitrogen. Seredych ${ }^{30}$ explanted amine functional groups on wood-origin activated carbon with oxidation by $50 \% \mathrm{HNO}_{3}$ and then treated with melamine and urea followed by carbonization at $950{ }^{\circ} \mathrm{C}$ in an inert atmosphere, and the density of basic surface groups was $0.688 \mathrm{mmol} \mathrm{g}^{-1}$. Kan-Nari ${ }^{31}$ doped nitrogen to activated carbon by treating in a stream of mixture of ammonia and air at temperatures of $400-800{ }^{\circ} \mathrm{C}$ and used it as alkaline catalyst in a Knoevenagel condensation and transesterification. Watanabe $^{\mathbf{1 1}}$ and Fujita ${ }^{32}$ prepared nitrogen-doped activated carbon 
via treatments of activated carbon with $\mathrm{H}_{2} \mathrm{O}_{2}$ and then ammonia at temperatures of $600-800{ }^{\circ} \mathrm{C}$ and the $\mathrm{N}$ were pyridine-, pyrrole-, and graphite-type nitrogen species.

Michael reaction with nitroalkanes is one of the most important reactions for formation of a carbon-carbon bond, involving the nucleophilic addition of a carbanion to $\alpha, \beta$ unsaturated carbonyl compounds, and is base-catalysed. ${ }^{33}$ In recent years, a variety of solid base catalysts has been reported, including potassium carbonate, ${ }^{34}$ amines anchored at surfaces, ${ }^{35}$ organic resins, ${ }^{36} \mathrm{KF}$ supported on $\alpha-\mathrm{Al}_{2} \mathrm{O}_{3},{ }^{37}$ and $\mathrm{KF}$ supported on hydrotalcite. ${ }^{38} \mathrm{~A}$ major drawback of some catalysts is that their use resulted in the increased formation of secondary products in the reactions. Reusable of the catalyst has seldom been demonstrated, which represents a severe limitation to its practical use.

In this work, we reported a convenient route (without high temperature and pressure) to construct an alkaline surface from the acidic activated carbon, with large amounts of nitrogencontaining groups, under the refluxed conditions with ethylenediamine at $117{ }^{\circ} \mathrm{C}$, and the catalytic performance and reusable ability of AC-N on Michael additions was studied.

\section{Experimental}

\subsection{Surface modification of activated carbon}

In general, $10 \mathrm{~g}$ activated carbon was added to $150 \mathrm{~mL}$ $12 \mathrm{~mol} \mathrm{~L}^{-1} \mathrm{HNO}_{3}$ in a three-necked flask connected with a condenser and thermometer, and stirred at $80{ }^{\circ} \mathrm{C}$ for 8 hours. After completion of the reaction, the reaction mixture was filtered, washed with water and ethanol, and then dried. The oxidized activated carbon was denoted as AC-O. The AC-O was added into $150 \mathrm{~mL}$ ethylenediamine and refluxed at $117^{\circ} \mathrm{C}$ for 8 hours. The mixture was filtered, washed with water and alcohol, and then AC-N was prepared after drying.

\subsection{Sample characterization}

2.2.1 Density of acid. The density of acid was quantified by Boehm titration. $^{39} 50 \mathrm{mg}$ AC-O was added into $20 \mathrm{~mL}$ $0.01 \mathrm{~mol} \mathrm{~L}^{-1} \mathrm{NaHCO}_{3}$ and sonicated for $30 \mathrm{~min}$. After filtering and washing with distilled water, the filtrate was titrated with $0.01 \mathrm{~mol} \mathrm{~L}^{-1} \mathrm{HCl}$ using bromocresol green-methyl red mixed indicator as the indicator.

2.2.2 Density of alkali. $50 \mathrm{mg}$ AC-N was added into $20 \mathrm{~mL}$ $0.01 \mathrm{~mol} \mathrm{~L}^{-1} \mathrm{HCl}$ and sonicated for $30 \mathrm{~min}$. After it was filtered and washed with distilled water, the filtrate was titrated with $0.01 \mathrm{~mol} \mathrm{~L}^{-1} \mathrm{NaOH}$ using phenolphthalein as the indicator.

2.2.3 Elemental analysis. The content of $\mathrm{N}$ analysis was analysed with vario EL III Elemental analyser (Germany). The tested conditions were: oxidation furnace temperature $1150{ }^{\circ} \mathrm{C}$,

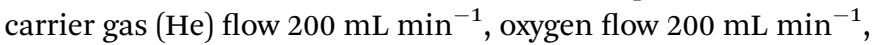
combustion time $90 \mathrm{~s}$.

2.2.4 Determination of specific surface area. The surface properties and surface area of the samples were characterized by $\mathrm{N}_{2}$ adsorption measurements at $77 \mathrm{~K}$ using a surface area analyzer (TriStar 3000$)$. The surface area $\left(S_{\mathrm{BET}}\right)$ was calculated from isotherms using the Brunauer-Emmett-Teller (BET) equation. The volume of liquid nitrogen corresponding to the amount adsorbed at a relative pressure of $P / P_{0}=0.99$ was defined as the total pore volume.

2.2.5 Thermogravimetric (TG). In order to plot TG and DTG curves for samples, NETZSCH STA 409 PC/PG thermal gravimetric analyzer was used. $20 \mathrm{mg}$ samples were heated, starting at room temperature and reaching up to $800{ }^{\circ} \mathrm{C}$ by increasing the temperature $10{ }^{\circ} \mathrm{C} \min ^{-1}$ gradually under $\mathrm{N}_{2}$.

2.2.6 Fourier transforms infrared (FT-IR). FT-IR spectroscopy analysis was performed using a Perkin Elmer 283 spectrometer. The samples for FT-IR analyses were prepared by mixing them with $\mathrm{KBr}$ powder and pressing the mixture into pellets. The FT-IR spectra were recorded between 4000 and $400 \mathrm{~cm}^{-1}$ (with a resolution of $4 \mathrm{~cm}^{-1}$ and acquisition rate of 20 scan per min).

2.2.7 X-ray photoelectron spectroscopy (XPS). A K-Alpha 1063 X-ray Photoelectron Spectrometer system was operated in a constant-pass energy mode at $50 \mathrm{eV}$ with a step size of $0.100 \mathrm{eV}$. Survey scans in the range of 10 to $1350 \mathrm{eV}$ were recorded. Prior to analysis, samples were dried at $105{ }^{\circ} \mathrm{C}$ and then kept under vacuum. ${ }^{\mathbf{4 0 , 4 1}}$

\subsection{Catalytic performance test}

The catalytic performance of AC-N in catalyzing the Michael addition reaction was tested. In general, a certain amount of substrates was added into a three-necked flask equipped with a thermometer and condenser. The effects of different temperature, time, and the catalyst amount on furfural conversion rate and 3-(nitromethyl)-2,3-dihydrofuran-2carbaldehyde selectivity were investigated. Different catalysts were used for comparation with AC-N in furfural Michael addition, and various substrates were used for testing the applicability of AC-N.

\section{Results and discussion}

\subsection{Structure and texture for AC-N}

3.1.1 Nitrogen adsorption-desorption studies. Surface areas of AC-O and AC-N were determined by means of the standard BET equation. The nitrogen adsorption-desorption curves are shown in Fig. 1. The $\mathrm{N}_{2}$ adsorption isotherm of the samples belonged to the type IV class of adsorption isotherm,

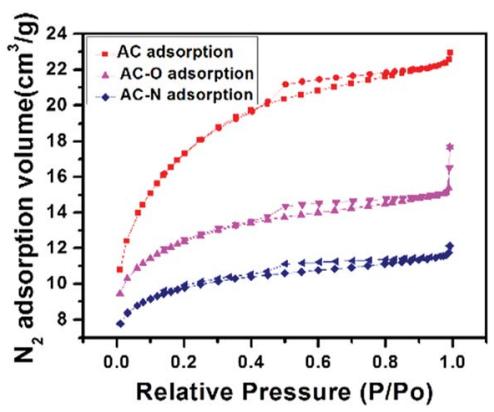

Fig. $1 \quad \mathrm{~N}_{2}$ adsorption-desorption isotherms for parent $\mathrm{AC}, \mathrm{AC}-\mathrm{O}$ and AC-N. 
which indicates the presence of a uniform mesoporous structure. ${ }^{29}$ At higher relative pressure, the adsorption capacity increased with the increase of the relative pressure. The adsorption isotherm showed an upturned "tail", and gradually intersects with the relative pressure $p / p_{0}=1$ axis, and desorption curves showed an obvious hysteresis loop, indicating that the three samples also had mesoporous structure. Fig. 2 shows results from the pore size distribution measurements for the samples. The results showed that oxidation of the carbon resulted in the decrease in the degree of mesoporous structure for AC-O and AC-N sample compared to AC. This is as a result of pore blockage in the mesoporous structure during the oxidation process. The porous structures of samples were shown in Table 1. After oxidation, the specific surface area of AC-O decreased to $614 \mathrm{~m}^{2} \mathrm{~g}^{-1}$ from $1286 \mathrm{~m}^{2} \mathrm{~g}^{-1}$ of $\mathrm{AC}$, and the pore volume simultaneously decreased to $0.38 \mathrm{~cm}^{3} \mathrm{~g}^{-1}$ from $0.77 \mathrm{~cm}^{3} \mathrm{~g}^{-1}$, which was due to the blocking of the pores by the surface complexes introduced by nitric acid treatment. ${ }^{7}$ After amination, the surface area of AC-N decreased to $418 \mathrm{~m}^{2} \mathrm{~g}^{-1}$, and the pore volume also decreased to $0.26 \mathrm{~cm}^{3} \mathrm{~g}^{-1}$, while the most probable pore size remained basically unchanged for the three carbon materials.

3.1.2 FT-IR. The FT-IR spectra of AC, AC-O, AC-N and AC mixed with 2-methylimidazole were shown in Fig. 3. It can be seen that the spectra showed a number of adsorption peaks, indicating the complex nature of the samples. In all samples, a strong absorption band was observed at around $3400 \mathrm{~cm}^{-1}$ and this was assigned to carboxylic group $\mathrm{O}-\mathrm{H}$ stretching. ${ }^{2}$ In the spectrum of AC, the absorption at $1720 \mathrm{~cm}^{-1}$ was attributed carboxylic acid group, which was also found in the sample ACO. In the samples AC and AC-O, the peaks at $1600 \mathrm{~cm}^{-1}$ were attributed to a quinone structure. ${ }^{7}$ The weak peaks around 1260 to $1060 \mathrm{~cm}^{-1}$ are due to the $\mathrm{C}=\mathrm{C}$ stretching that can be

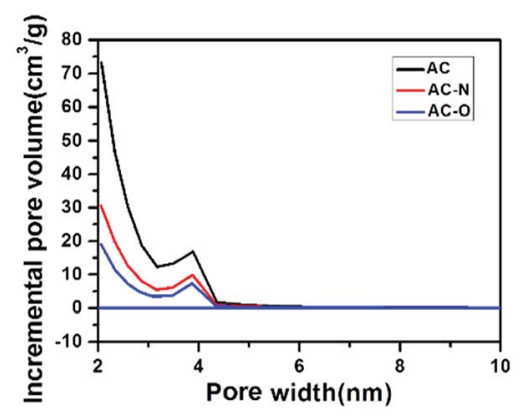

Fig. 2 Pore size distribution for the samples.

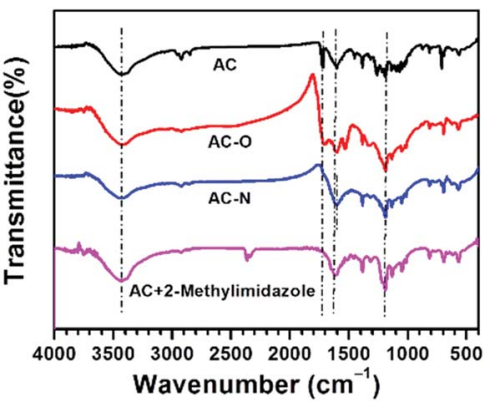

Fig. 3 FT-IR spectra for the AC, AC-O and AC-N.

attributed to the presence of aromatic rings in AC. After oxidation, the weak peaks around 1260 to $1060 \mathrm{~cm}^{-1}$ disappeared, which indicated that oxidization process destroyed the $\mathrm{C}=\mathrm{C}$ on the AC surface. In all the samples except AC, the broad peak around $1200 \mathrm{~cm}^{-1}$ may be attributed to different functional groups containing single-bonded oxygen atoms such as phenols, ethers, and lactones, ${ }^{6}$ or single-bonded nitrogen atoms such as $\mathrm{C}-\mathrm{N},-\mathrm{NH}$ and $-\mathrm{NH}_{2}{ }^{2,7,10}$ For the sample AC-N, there were no absorption peaks at 1720 and $1600 \mathrm{~cm}^{-1}$, while a new absorption peak appeared at $1604 \mathrm{~cm}^{-1}$, which was attributed to $\mathrm{C}-\mathrm{N}$ stretching vibration. ${ }^{10}$ The absorption of the $\mathrm{N}-\mathrm{H}$ stretching vibration also appeared at around $3400 \mathrm{~cm}^{-1}$, which nearly overlapped with that of O-H stretching. The FT-IR spectra of AC mixed with 2-methylimidazole was indistinguishable from that of AC-N, which indicated that $\mathrm{N}$-containing groups on the surface of AC-N were similar to the structure of 2methylimidazole.

3.1.3 Density of acid and alkali. Density of acid and alkali in AC, AC-O and AC-N were measured by Boehm titration: the results were shown in Table 1 . The texture parameters of the material are also shown in Table 1 . These results indicated that there was absolutely no acidic center and alkali center on the AC surface, while certain $\mathrm{H}^{+}$acidic centers were detected in AC-O. After the amination with ethylenediamine, the acidic center on AC-O surface, carboxyl groups were completely destroyed and converted to basic centers.

3.1.4 Elemental analysis. The contents of nitrogen in AC, AC-O and AC-N were analyzed with elemental analyzer. The results were shown in Table 1 . As shown, $\mathrm{N}$ content of AC-O was slightly lower than that of AC caused by oxidization. After treated with ethanediamine, the $\mathrm{N}$ content of AC-N was increased to $10.3 \%$, which indicated that $\mathrm{N}$-contained group was grafted on carbon successfully.

Table 1 The surface acid-base properties and texture features of samples

\begin{tabular}{|c|c|c|c|c|c|c|c|}
\hline $\mathrm{AC}$ & 0.03 & 0.00 & 0.26 & 0.56 & 1286 & 0.77 & 2.4 \\
\hline AC-N & 0.00 & 0.96 & 9.38 & 10.3 & 418 & 0.26 & 2.5 \\
\hline
\end{tabular}

${ }^{a} c_{\mathrm{NA}}$ represents for concentration of alkali site caused with $\mathrm{N} .{ }^{b} \mathrm{~N}$ represents for $\mathrm{N}$ content analyzed with XPS. ${ }^{c} \mathrm{~N}$ represents for $\mathrm{N}$ content analyzed with elemental analyzer. 
3.1.5 XPS. To understand the surface chemistry of AC-N, the nature of $\mathrm{C}, \mathrm{O}$ and $\mathrm{N}$ species at the surface of different samples (including AC-N, AC-N mixed with 2-methylimidazole and AC mixed with ethylenediamine) were investigated by XPS. The survey spectra were shown in Fig. 4, and the C1s and N1s XPS spectra are shown in Fig. 5. As shown, the C1s of AC mainly consisted with features at 284.8, 286.1 and $287.9 \mathrm{eV}$, corresponding to $\mathrm{sp}^{2} \mathrm{C}, \mathrm{C}-\mathrm{O}(\mathrm{C}-\mathrm{N})$ and $\mathrm{C}=\mathrm{O}(\mathrm{C}=\mathrm{N})$ groups, ${ }^{6,29}$ respectively. For AC-N, the peaks at 286.1 and $287.9 \mathrm{eV}$ were enhanced after the oxidation and amination of AC, which indicated that the surface functional groups changed a little during the treatment of AC. The N1s peaks of AC-doped methyl imidazole mainly consist of three peaks, which were located at 398.7, 399.5 and $401.4 \mathrm{eV}$, respectively, corresponding to pyridine-type $(\mathrm{C}-\mathrm{N}=\mathrm{C})$, pyrrole-type $(\mathrm{C}-\mathrm{NH}-\mathrm{C})$ and graphitetype nitrogen..$^{\mathbf{9}, 11,30,31,35}$ As expected, after modification of AC to AC-N, the corresponding N1s peaks in methylimidazole were shifted $0.2 \mathrm{eV}$ towards the low energy region, which indicated that a certain amount of imidazole structure existed in AC-N. A strong peak appeared at $400.1 \mathrm{eV}$ in $\mathrm{AC}-\mathrm{N}$, corresponding to the nitrogen in $\mathrm{C}-\mathrm{NH}_{2},{ }^{31}$ indicating that some of the amino groups in AC-N did not dehydrate to form a ring.

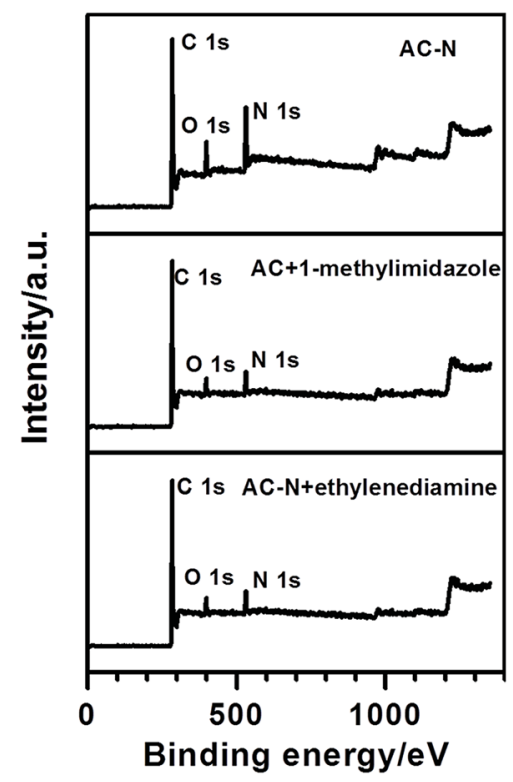

Fig. 4 Survey of $A C-N$ and $A C$ mixed with 2-methylimidazole and ethylenediamine.

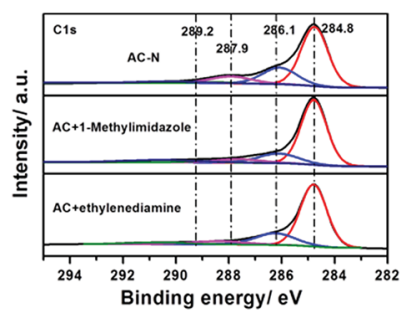

(a)

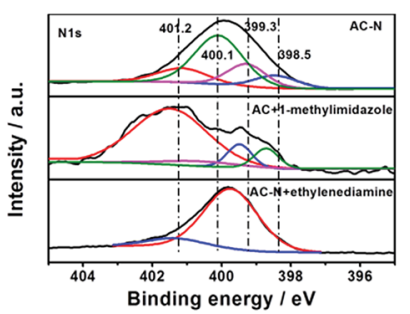

(b)
Fig. $5 \mathrm{C} 1 \mathrm{~s}(\mathrm{a})$ and N1s (b) XPS spectra of AC-N, AC mixed with 2methylimidazole and $A C$ mixed with ethylenediamine.
3.1.6 TG-DTG. The thermal stability of the different samples was determined by TG-DTG and depicted in Fig. 6 . The thermogravimetric analysis (TG) weight loss stages were observed in all samples. A significant weight loss below $100{ }^{\circ} \mathrm{C}$ can be attributed to elimination of the adsorbed water: it was notable that the waterloss temperature of AC-O $\left(103.5^{\circ} \mathrm{C}\right)$ and AC-N $\left(98.7^{\circ} \mathrm{C}\right)$ was higher than $\mathrm{AC}\left(78.3{ }^{\circ} \mathrm{C}\right)$, indicating a higher affinity for water. The weight-loss peak at $350^{\circ} \mathrm{C}$ was present in AC-N, which was higher than that of in AC-O $\left(306^{\circ} \mathrm{C}\right)$, while there was no peak presented in sample AC. The differences are mainly caused by the organic components generated by oxide and alkaline modification processes, which also showed that the alkaline function groups were more stable than acidic oxygen functional groups. According to Fig. 6, hydrophilic groups were generated on the AC surface in the oxidation process, while the surface structure was damaged at a certain degree at the edge of the structure to produce a certain amount of components which were easily decomposed. After amination, the peak of water loss was lower than that of AC-O, and the other weight-loss peak was increased, which indicated that the surface structure of AC-N was further changed and the hydrophilicity was slightly lower than that of AC-O. The thermal stability of the new component was enhanced to a certain extent.

According to the texture and spectrum analysis of AC, AC-O and AC-N, the surface groups of the material were shown as Fig. 7. After oxidation, the content of oxygen-containing functional groups on the AC-O surface was increased, including carboxyl groups, hydroxyl groups, carbonyl groups, lactone groups and so on. After amination treatment, the carboxyl group on AC-O surface reacted with ethylenediamine to form an amide structure, and further dehydration into the ring occurred to form a similar imidazole structure. Part of carbonyl group reacted with ethylenediamine to form an amino group in the surface of AC-N.

\subsection{Catalyst performances}

3.2.1 The catalytic performance of AC-N on furfural Michael additions. Michael addition is a very efficient, high

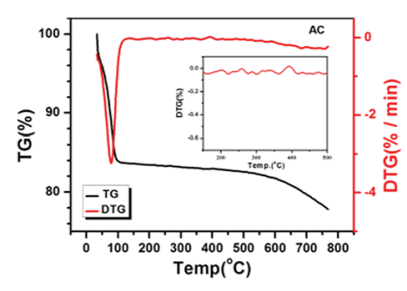

(a)

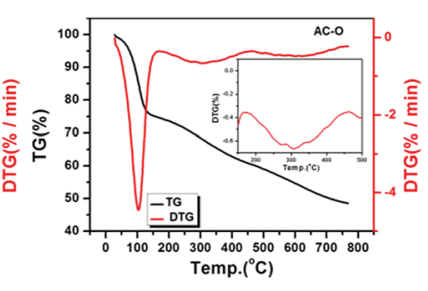

(b)

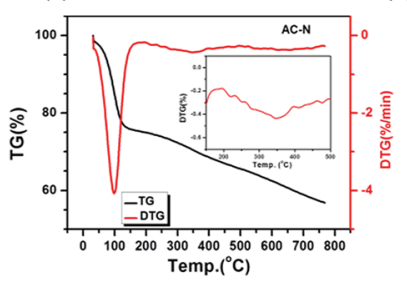

(c)

Fig. 6 TG and DTG analysis of (a) AC; (b) AC-O; (c) AC-N. 


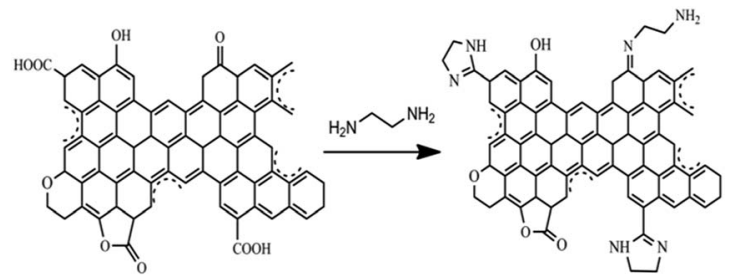

Fig. 7 Scheme of preparing AC-N.

atom economy carbon-carbon formation reaction in organic synthesis, so the development of the Michael addition reaction has attracted the attention of organic chemists for the past several decades. In this work, the Michael addition reaction was studied using AC-N as a solid base catalyst. The reaction scheme was shown in Fig. 8.

The effects of temperature, time, and catalyst dosage on the conversion of furfural and the selectivity of 3-(nitromethyl)-2,3dihydrofuran-2-carbaldehyde were investigated. From the results in Fig. 9, it can be seen that the conversion of furfural and the selectivity of 3-(nitromethyl)-2,3-dihydrofuran-2carbaldehyde were not changed at different temperatures when the reaction time was $7 \mathrm{~h}$. Neither of the conversion and the selectivity changed when the temperature was above $120{ }^{\circ} \mathrm{C}$. Therefore, the reaction conditions were chosen as $120^{\circ} \mathrm{C}$ with a reaction time of $7 \mathrm{~h}$. When the amount of catalyst was less than $2.0 \mathrm{~mol} \%$, the conversion of furfural and the selectivity of 3-(nitromethyl)-2,3-dihydrofuran-2-carbaldehyde increased with the amount of catalyst. When the amount of the catalyst was more than $2.0 \mathrm{~mol} \%$, neither of these was changed.

3.2.2 Catalyst reusability. One of the main advantages of heterogeneous solid catalysts is that they can be easily recovered from the reaction mixture and can be regenerated for reuse. In the present study, the catalyst AC-N was washed thoroughly with ethanol, followed by vacuum drying for $12 \mathrm{~h}$. The catalyst was then reused for the next run under the same reaction

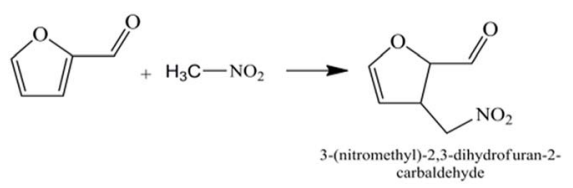

Fig. 8 Michael reaction of nitromethane on furfural.

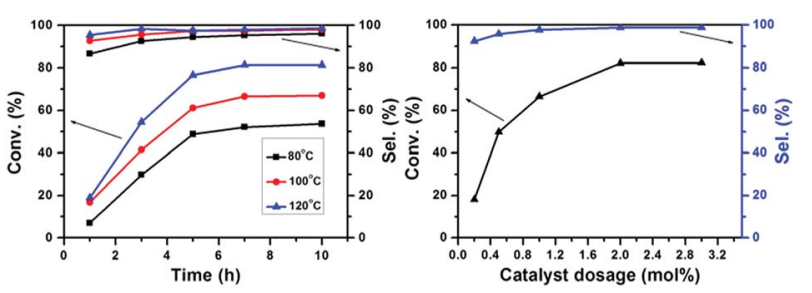

Fig. 9 Effect of temperature, time, and catalyst dosage on conversion of furfural and selectivity of 3-(nitromethyl)-2,3-dihydrofuran-2carbaldehyde.

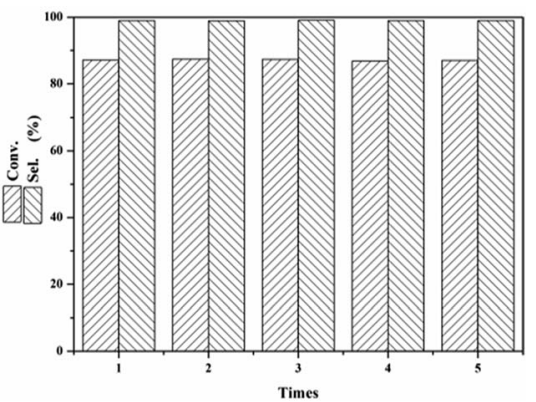

Fig. 10 Reusability of AC-N for Michael addition of furfural.

Table 2 Effect of different catalysts and substrates on Michael addition $^{a}$

\begin{tabular}{lllll}
\hline Catalysts & Substrates & Time (h) & Conv. (\%) & Sel. (\%) \\
\hline None & Furfural & 10 & 1 & 70 \\
2-Methylimidazole & Furfural & 10 & 23 & 77 \\
$\mathrm{KOH}$ & Furfural & 10 & 54 & 60 \\
$\mathrm{Cs}_{2} \mathrm{CO}_{3}$ & Furfural & 10 & 46 & 62 \\
$\mathrm{CaO}$ & Furfural & 10 & 35 & 58 \\
$\mathrm{AC}-\mathrm{N}$ & Furfural & 7 & 87 & 99 \\
$\mathrm{AC}-\mathrm{N}$ & Citral & 7 & 93 & 93 \\
AC-N & Crotonaldehyde & 7 & 96 & 99 \\
AC-N & trans-2-Pentenal & 7 & 96 & 99 \\
AC-N & 3-Methyl-2-butenal & 7 & 95 & 97 \\
& &
\end{tabular}

${ }^{a}$ Reaction conditions: mol (nitromethane/aldehyde) $=3$, catalyst $2 \mathrm{~mol} \%, 120^{\circ} \mathrm{C}$.

conditions. As shown in Fig. 10, after 5 cycles, the conversion and selectivity of furfural remained unchanged at $87 \%$ and $99 \%$ respectively, which means excellent stability of the catalyst on furfural in the Michael addition reaction.

3.2.3 Catalysts comparation for furfural Michael addition and substrates applicability catalyzed with AC-N. The effect of commonly used catalysts on the reaction of furfural with nitromethane were studied and compared with that of AC-N. The results were shown in Table 2. According to Table 2, the conversion of furfural was $87 \%$ and the selectivity of the 3 (nitromethyl)-2,3-dihydrofuran-2-carbaldehyde was $99 \%$ catalyzed with AC-N. Under the same conditions, the conversion of furfural was $54 \%, 46 \%, 35 \%$ and the selectivity of $3-$ (nitromethyl)-2,3-dihydrofuran-2-carbaldehyde was 60\%, 62\%, $58 \%$ using $\mathrm{KOH}, \mathrm{Cs}_{2} \mathrm{CO}_{3}, \mathrm{CaO}$ as inorganic base catalysts, respectively. The conversion of furfural was only $23 \%$ and the selectivity of the 3-(nitromethyl)-2,3-dihydrofuran-2carbaldehyde was $77 \%$ using methylimidazole as catalyst. The experimental results showed that AC-N expressed better catalytic performance than those commonly used base catalyst. As a solid catalyst, AC-N had the advantage of being easily separated from the reaction system. With AC-N as a catalyst, the Michael addition of different substrates was studied. As shown in Table 2, AC-N showed better catalysis performance in chain olefine aldehyde. 


\section{Conclusions}

A new activated carbon material containing a certain amount of imidazole groups and amine groups on surface was prepared via oxidation using $\mathrm{HNO}_{3}$ and then amination using ethanediamine under atmospheric pressure with activated carbon as a raw material. Compared with the related previously-published research reports, the route reported in this research avoided treatment at high temperature and high pressure. The structure analysis showed that AC-N contained a certain amount of imidazole structure and the results showed that the $\mathrm{N}$ content of AC-N was $10.3 \%$. The surface alkali density of the material was $0.96 \mathrm{mmol} \mathrm{g}^{-1}$ and the specific surface area was $418 \mathrm{~m}^{3} \mathrm{~g}^{-1}$.

As a solid base catalyst, AC-N showed an excellent catalytic performance on the Michael addition reaction of furfural, which was better than that of 2-methylimidazole, a homogeneous alkaline catalyst, and also better than that of inorganic strong base $\mathrm{KOH}$ under the same conditions. After 5 cycles, the conversion of furfural remained at around $87 \%$ and the selectivity was $99 \%$ of 3-(nitromethyl)-2,3-dihydrofuran-2-carbaldehyde, which means excellent stability of the catalyst on furfural for the Michael addition reaction.

\section{Conflicts of interest}

There are no conflicts to declare.

\section{Acknowledgements}

This work was supported by the National Natural Science Foundation of China (No. 21776068 and 21606082), the Scientific Research Fund of Hunan Provincial Education Department (17C0951 and 15B050), Hunan Provincial Innovation Foundation For Postgraduate (No. CX2016B166) and Collaborative Innovation Center of New Chemical Technologies for Environmental Benignity and Efficient Resource Utilization.

\section{References}

1 T. M. Alslaibi, I. Abustan, M. A. Ahmad and A. A. Foul, J. Chem. Technol. Biotechnol., 2013, 88, 1183-1190.

2 P. Chingombe, B. Saha and R. J. Wakeman, Carbon, 2005, 43, 3132-3143.

3 S. W. Nam, D. J. Choi, S. K. Kim, N. Her and K. D. Zoh, J. Hazard. Mater., 2014, 270, 144-152.

4 S. Haydar, M. A. Ferro-GarcíA, J. Rivera-Utrilla and J. P. Joly, Carbon, 2003, 41, 387-395.

5 Y. F. Jia, A. B. Xiao and K. M. Thomas, Langmuir, 2002, 18, 470-478.

6 J. P. Chen and S. Wu, Langmuir, 2004, 20, 2233-2242.

7 J. W. Shim, S. J. Park and S. K. Ryu, Carbon, 2001, 39, 16351642.

8 W. Qi and D. Su, ACS Catal., 2014, 4, 415-429.

9 M. Kubota, A. Hata and H. Matsuda, Carbon, 2009, 47, 28052811.

10 Y. Liu, Z. Hu, K. Xu, X. Zheng and Q. Gao, Acta Phys.-Chim. Sin., 2008, 24, 1143-1148.
11 H. Watanabe, S. Asano, S. Fujita, H. Yoshida and M. Arai, ACS Catal., 2015, 5, 2886-2894.

12 J. J. Ternero-Hidalgo, J. M. Rosas, J. Palomo, M. J. ValeroRomero, J. Rodríguez-Mirasol and T. Cordero, Carbon, 2016, 101, 409-419.

13 N. Wibowo, L. Setyadhi, D. Wibowo, J. Setiawan and S. Ismadji, J. Hazard. Mater., 2007, 146, 237-243.

14 R. R. V. A. Rios, D. E. Alves, I. Dalmázio, S. F. V. Bento, C. L. Donnici and R. M. Lago, Mater. Res., 2003, 6, 129-135.

15 M. A. Álvarez-Merino, V. López-Ramón and C. MorenoCastilla, J. Colloid Interface Sci., 2005, 288, 335-341.

16 G. Yadavalli, H. Lei, Y. Wei, L. Zhu, X. Zhang, Y. Liu and D. Yan, Biomass Bioenergy, 2017, 98, 53-60.

17 A. A. Daifullah, S. M. Yakout and S. A. Elreefy, J. Hazard. Mater., 2007, 147, 633-643.

18 D. Lozano-Castelló, M. A. Lillo-Ródenas, D. Cazorla-Amorós and A. Linares-Solano, Carbon, 2001, 39, 741-749.

19 H. Teng and L. Y. Hsu, Ind. Eng. Chem. Res., 1999, 38, 29472953.

20 T. Otowa, Y. Nojima and T. Miyazaki, Carbon, 1997, 35, 1315-1319.

21 S. J. Park and Y. S. Jang, J. Colloid Interface Sci., 2002, 249, 458-463.

22 A. L. Cazetta, A. M. M. Vargas, E. M. Nogami, M. H. Kunita, M. R. Guilherme, A. C. Martins, T. L. Silva, J. C. G. Moraes and V. C. Almeida, Chem. Eng. J., 2011, 174, 117-125.

23 C. D. E. S. Barbosa, J. R. Corrêa, G. A. Medeiros, G. Barreto, K. G. Magalhaes, A. L. Oliveira, J. Spencer, M. O. Rodrigues and B. A. D. Neto, Chem.-Eur. J., 2015, 21, 5055-5060.

24 Y. J. Gao, X. Chen, J. G. Zhang and N. Yan, ChemPlusChem, 2015, 80, 1556-1564.

25 B. Li, F. Dai, Q. F. Xiao, L. Yang, J. M. Shen, C. M. Zhang and M. Cai, Energy Environ. Sci., 2016, 9, 102-106.

26 W. Wang, H. Quan, W. Gao, R. Zou, D. Chen, Y. Dong and L. Guo, RSC Adv., 2017, 27, 16678-16687.

27 J. Lahaye, G. Nansé, A. Bagreev and V. Strelko, Carbon, 1999, 37, 585-590.

28 B. Stöhr, H. P. Boehm and R. Schlögl, Carbon, 1991, 29, 707720.

29 J. Park, Y. Nabae, T. Hayakawa and M. Kakimoto, ACS Catal., 2014, 4, 3749-3754.

30 M. Seredych, D. Hulicova-Jurcakova, Q. L. Gao and T. J. Bandosz, Carbon, 2008, 46, 1475-1488.

31 N. Kan-Nari, S. Okamura, S. I. Fujita, J. I. Ozaki and M. Arai, Adv. Synth. Catal., 2010, 352, 1476-1484.

32 S. I. Fujita, H. Watanabe, A. Katagiri, H. Yoshida and M. Arai, J. Mol. Catal. A: Chem., 2014, 393, 257-262.

33 H. Guo, X. Li, J. L. Wang, X. H. Jin and X. F. Lin, Tetrahedron, 2011, 42, 8300-8303.

34 G. Bosica and K. Polidano, J. Chem., 2017, 2017, 6267036.

35 A. Corma, S. Iborra, I. Rodriguez, M. Iglesias and F. Sanchez, Catal. Lett., 2002, 82, 237-242.

36 R. Ballini, P. Marziali and A. Mozzicafreddo, J. Org. Chem., 1996, 61, 3209-3211.

37 J. M. Clacens, D. Genuit, L. Delmotte, A. G. Ruiz, G. Bergeret, R. Montiel, J. Lopez and F. Figueras, J. Catal., 2004, 221, 483490. 
38 B. M. Choudary, B. Kavita, N. S. Chowdari, B. Sreedhar and M. L. Kantam, Catal. Lett., 2002, 78, 373-377.

39 I. Ogino, Y. Suzuki and S. R. Mukai, Catal. Today, 2018, 314, 41 R. J. J. Jansen and H. V. Bekkum, Carbon, 1995, 33, 102162-69.
40 C. L. Mangun, K. R. Benak, J. Economy and K. L. Foster, Carbon, 2001, 39, 1809-1820. 1027. 